\title{
PERANCANGAN FILM ANIMASI PUNAKAWAN SEBAGAI SIMBOL KEBIJAKSANAAN
}

\author{
Danny Surachandra' ${ }^{1)}$, Yayah Rukiah ${ }^{2)}$, FC Ndaru Ranuhandoko ${ }^{3)}$ \\ Program Studi Desain Komunikasi Visual \\ Fakultas Bahasa dan Seni, Universitas Indraprasta PGRI \\ Jl. Nangka No. 58 C, Tanjung Barat, Jakarta Selatan, 12530, Indonesia \\ dannyschandra@gmail.com
}

\begin{abstract}
Abstrak
Tujuan penelitian untuk merancang film animasi asal-usul Punakawan sebagai simbol kebijaksanaan untuk pendidikan budaya bagi anak dan remaja. Metode penelitian yang digunakan adalah jenis penulisan kualitatif deskriptif. Data yang didapatkan kemudian dianalisis terkait dengan media yang sudah ada. Punakawan adalah tokoh dagelan dan penasihat atau dijadikan contoh dalam sajian pagelaran wayang. Belum banyak informasi yang menjelaskan tentang pewayangan khususnya tokoh Punakawan. Dapat disimpulkan bahwa visualisasi film animasi dapat menarik minat lebih banyak dan langsung berpengaruh pada anak dan remaja. Film animasi Punakawan ini berdurasi 3 sampai 6 menit. Film animasi ini dibuat untuk anak dan remaja dengan usia 12 sampai 15 tahun. Unsur yang terdapat di dalam film animasi ini menggunakan gaya karakter kartun semirealis, sehingga menjadi rangkaian gambar yang memiliki kemampuan menarik untuk menyampaikan ide dan cerita. Hasil dari penelitian ini adalah perancangan film animasi asal-usul Punakawan sebagai simbol kebijaksanaan untuk pendidikan budaya agar dapat memperkenalkan dan menambah film animasi Punakawan kepada anak dan remaja agar generasi sekarang serta mengenalkan kebudayaan Indonesia.
\end{abstract}

Kata Kunci: animasi, wayang, Punakawan, simbol kebijaksanaan

\begin{abstract}
The research objective is to design an animated film from the origins of Punakawan as a symbol of wisdom for cultural education for children and adolescents. The research method used is descriptive qualitative writing. The data obtained were then analyzed in relation to existing media. Punakawan is a joke character and advisor or used as an example in wayang performances. There is not much information that explains the puppetry especially the Punakawan figures. It can be concluded that the visualization of animated films can attract more interest and directly affect children and adolescents. This Punakawan animation film is 3 to 6 minutes long. This animated film is made for children and adolescents aged 12 to 15 years. The elements contained in this animated film use a semirealist cartoon character style, so that it becomes a series of pictures that have an interesting ability to convey ideas and stories. The result of this research is the design of an animated film from Punakawan's origins as a symbol of wisdom for cultural education in order to introduce and add Punakawan animated films to children and adolescents so that the current generation can introduce Indonesian culture.).
\end{abstract}

Keywords: animation, puppet, Punakawan, symbol of wisdom

Correspondence author: Yayah Rukiah, rukiah.yayah13@gmail.com, Jakarta, and Indonesia. 


\section{PENDAHULUAN}

Menurut penelitian para ahli sejarah kebudayaan, budaya wayang merupakan budaya asli Indonesia, khususnya di Pulau Jawa. Keberadaan dalam wayang sudah berabad-abad sebelum agama Hindu masuk ke Pulau Jawa. Walaupun cerita wayang yang popular di masyarakat masa kini merupakan adaptasi dari karya sastra India, yaitu Ramayana dan Mahabarata. Kedua induk cerita itu dalam pewayangan banyak mengalami perubahan dan penambahan untuk menyesuaikan dengan falsafah asli Indonesia. Penyesuaian konsep filsafat ini juga menyangkut pada pandangan filosofis masyarakat Jawa terdapat kedudukan para dewa dalam pewayangan. Para dewa dalam pewayangan bukan lagi merupakan sesuatu yang bebas dari salah, melainkan seperti juga makhluk Tuhan lainnya, kadang-kadang bertindak keliru, dan bisa jadi khilaf. Hadirnya tokoh Punakawan dalam pewayangan sengaja diciptakan para budayawan Indonesia (tepatnya budayawan Jawa) untuk memperkuat konsep filsafat bahwa di dunia ini tidak ada makhluk yang benar-benar baik, dan yang benar-benar jahat. Setiap makhluk selalu menyandang unsur kebaikan dan kejahatan (Wangi, 1999: 1407).

Sunarto (Sunarto, 2012: 242) mengatakan secara etimologi, Panakawan berasal dari kata pana yang memiliki pengertian cerdik, mengetahui, paham, jelas sekali atau cermat dalam pengamatan. Pana berasal dari kata purna yang memiliki arti sempurna atau tuntas dan kata kawan yang berarti teman mengungkapkan bahwa kelompok wayang ini disebut dengan wayang prepat atau parepat, karena tokoh-tokoh dalam kelompok ini berjumlah empat yang senantiasa dijadikan kawan untuk berunding dalam segala masalah sulit dan pelik yang dihadapi oleh tokoh satrianya. Di samping itu kelompok wayang ini dinamakan wayang dagelan, karena kelompok wayang ini senantiasa dijadikan alat untuk ndagel atau melawak oleh dhalang.

Tokoh Panakawan ada yang diceritakan sebagai Dewa Ngéjawatah, seorang manusia berjiwa dewa dan berkekuatan dewa. Para Punakawan dicintai oleh para satria karena kemampuan dalam memberikan saran untuk memecahkan suatu masalah. Di samping itu diceritakan bahwa para satria akan berhasil melaksanakan tugas darmanya, jika diiringi oleh Panakawan. Banyak lakon wayang kulit Purwa, seperti lakon Petruk dukun, lakon Wahyu Setyo Wacana, lakon Semar membangun kahyangan dan lakon lainnya. Secara garis besar menceritakan ketika para satria meninggalkan Panakawan, ia akan mendapat kesulitan dan kesusahan. Akibatnya tidak hanya diri sendiri yang celaka, tetapi keluarga mengalami penderitaan dan negara akan mengalami kekacauan. Hal ini menunjukkan bahwa peran yang dibawakan oleh para Panakawan khususnya prepat dalam turut serta memelihara kedamaian dunia sangat besar. Oleh karena itu tokoh Panakawan sangat disayangi dan dihormati oleh para satria, bahkan hubungan satria dan Panakawan menjadi simbol manunggaling kawula gusti (Sunarto, 2012 : 251-252).

Punakawan secara karateristik sebenarnya mewakili profil umum manusia. Mereka adalah tokoh multi-peran yang dapat menjadi penasihat para penguasa atau satria bahkan dewa. Mereka juga berperan sebagai penghibur, kritikus sekaligus menjadi penyampai kebenaran, kebajikan dan penganjur keutamaan. Dari mereka kita dapat banyak mengambil hikmah bahkan dengan tanpa terasa sebenarnya menertawakan diri sendiri (Kresna, 2012: 17).

Jika melihat ke biografi karakter-karakter Punakawan, mereka asalnya adalah orangorang yang menjalani metamorfosis atau perubahan karakter yang berangsur-angsur hingga menjadi sosok yang sederhana, namun memiliki kedalaman ilmu yang luar biasa. Para Dewa pun tidak ada yang berani marah kepada Bagong, sekalipun sosok ini sering mengkritik mereka dengan humor-humor yang sarat kebijaksanaan. Walaupun penyampaiannya dalam memberi pesan-pesan bermakna tersebut secara jenaka bahkan dengan berlaku konyol dan vulgar sekalipun (Kresna, 2012: 18).

Tokoh seni wayang yang akan menjadi bahasan dalam penelitian ini adalah tokoh Punakawan karena tokoh tersebut memiliki keunikan yaitu memainkan peran dagelan yang lucu dan menghibur, tetapi dihormati oleh para kesatria karena dapat memberikan nasihat yang bijaksana. Oleh karena itu tertarik untuk melakukan penelitian pada tokoh wayang tersebut.

Ada beberapa faktor mendasar yang menyebabkan masyarakat kurang mengapresiasi wayang, yaitu: aspek kebahasaan, muatan cerita, dan durasi pertunjukannya. salah satu permasalahannya adalah bahasa, bahasa Jawa dengan struktur rumit menjadi kendala bagi 
masyarakat luas, terutama generasi muda untuk memahami dan menangkap makna cerita. Berdasarkan observasi yang dilakukan pagelaran wayang kulit, wayang golek dan wayang orang dengan judul Festival Dalang Bocah Tingkat Nasional ke 10 di Panggung Candi Bentar, Taman Mini Indonesia Indah, Jakarta Timur, pada 21 September 2019. dari awal pementasannya menggunakan bahasa Jawa sehingga alur cerita yang disajikan hampir tidak dimengerti oleh beberapa penonton yang tidak paham bahasa Jawa.

Banyaknya muatan cerita wayang yang lebih berorientasi pada pola pikir orang tua karena cerita yang dibeberkan mengandung pesan yang lebih dipahami orang tua dari pada generasi muda. Pada persoalan lain, masyarakat disuguhi pertunjukan wayang berdurasi lama menyebabkan rasa jenuh. Mereka tidak memiliki ketahanan untuk berlama-lama mengapresiasi wayang, karena faktor pekerjaan ataupun rutinitas sekolah. Kondisi eksternal dan internal inilah yang menjadi tantangan bagi upaya pengembangan wayang Indonesia agar diminati masyarakat berbagai kalangan dan menyesuaikan perkembangan zaman di era industri digital. Jika minat masyarakat terhadap wayang sudah mulai luntur, maka ajaran dalam Punakawan pun akan sulit tersampaikan, padahal ajaran Punakawan berisikan nilai dan pesan moral yang baik.

Di era globalisasi ini, teknologi komunikasi dan informasi dapat dengan mudah menyebarkan kebudayaan ke seluruh penjuru dunia sehingga berpengaruh pada pola pikir dan tindakan manusia yang berdampak pada pembentukan karakter bangsa. Media sosial seperti youtube menyajikan berbagai macam tontonan sesuai dengan keinginan penggunanya termasuk pementasan wayang. Maka dari itu, keterbatasan waktu dan tempat pagelaran wayang sudah tidak dapat lagi dijadikan alasan bagi generasi muda untuk mengenal lebih jauh tentang tingginya nilai yang terkandung dalam pewayangan, ditambah lagi dengan beberapa video yang menyajikan pementasan wayang menggunakan bahasa Indonesia.

Meskipun sudah ada beberapa pementasan wayang menggunakan bahasa Indonesia yang dapat dengan mudah diakses oleh berbagai kalangan, namun masih sedikit media yang menyajikan film animasi lakon-lakon dari pewayangan, salah satunya menggunakan multimedia yang merupakan penggabungan dari tiga elemen yaitu suara, gambar dan teks untuk saling menguatkan dalam menyalurkan pesan (pengetahuan, keterampilan dan sikap) serta dapat merangsang pikiran, perasaan, perhatian dan kemauan pengguna sehingga secara sengaja proses belajar terjadi, bertujuan dan terkendali (Didik dalam Saptodewo, 2015: 151).

Cara melestarikan budaya dapat melalui sebuah pendidikan, seperti mempelajari kesenian tradisional di sekolah. Film animasi juga dapat menjadi media yang digunakan untuk mempelajari kesenian tradisional secara lebih menarik. Sehingga anak dan remaja lebih berminat untuk mengenal kesenian tradisional khususnya wayang.

Berdasarkan uraian diatas, maka akan diciptakan karya film animasi asal-usul Punakawan. setelah melakukan wawancara dan berbagai kegiatan dari pagelaran wayang, salah satunya Sanggar Nirmalasari Cinere Depok. Animasi akan dibuat dengan teknik frame to frame dan motion yang mempresentasikan cerita asal-usul tokoh wayang Punakawan.

Film animasi asal-usul Punakawan menjadi salah satu bentuk alternatif pengembangan wayang Indonesia untuk masyarakat saat ini. Inovasi pertunjukan film animasi sebagai respons terhadap era industri digital, dengan mengeksplorasi kekuatan seni tradisi yang dikemas dengan teknologi modern untuk menghasilkan produk seni budaya yang dapat memenuhi selera pasar. Disinilah pentingnya berkreasi wayang dengan paradigma industri kreatif. Film animasi asal-usul Punakawan dapat dijadikan produk industri kreatif untuk menjangkau segmen masyarakat yang lebih luas.

Film animasi asal-usul Punakawan menjadikan modernisasi dan perkembangan teknologi sebagai peluang untuk melanjutkan perjuangan yang pernah dilakukan oleh para wali dalam menyajikan hiburan yang mendidik dengan cara yang menarik, mudah didapat, mudah dimengerti oleh kalangan masyarakat, dan tanpa adanya unsur paksaan. Perancangan film animasi tentang proses terbentuknya asal-usul dianggap sebagai cara efektif untuk mempertahankan budaya, memperbesar minat dan rasa ingin tahu lebih jauh terhadap nilai yang terkandung dalam pewayangan terutama tentang kebijaksanaan dan pesan moral yang terdapat dalam alur cerita tersebut. 
Dari media film animasi yang ada saat ini, walaupun animasi lakon Punakawan sudah cukup banyak tetapi masih kurangnya animasi yang menjelaskan mengenai cerita asal-usul tokoh Wayang Punakawan. Oleh sebab itu, disimpulkan bahwa agar anak dan remaja mengetahui dan mempelajari pewayangan khususnya asal-usul tokoh Punakawan, maka perlu ada solusi berupa media yang menarik, yaitu berupa film animasi, yang di dalamnya menggambarkan mengenai dunia wayang hingga bagaimana tokoh Punakawan terbentuk. Dengan begitu, dapat menarik minat seseorang untuk ikut mempelajari dan berkontribusi khususnya pada anak dan remaja untuk melestarikan salah satu kesenian tradisional Indonesia ini.

Film animasi ini akan menceritakan asal-usul terbentuknya tokoh Punakawan dan kebijaksanaan yang dapat diambil dari kisah terbentuknya Punakawan. Film animasi ini dibuat sedemikian rupa sehingga mudah dimengerti baik oleh anak dan remaja atau masyarakat umum dengan memperlihatkan secara jelas audio-visualnya, agar masyarakat juga paham pentingnya melestarikan dan menjaga kesenian tradisional Indonesia.

Alur cerita akan disajikan dengan mengambil dari sekian banyak versi yang sudah ada dalam bentuk tertulis, namun dalam perancangan film animasi asal-usul Punakawan akan dibuat menjadi lebih sederhana, terutama dalam durasi waktu, alur cerita dan bahasa yang digunakan menyesuaikan dengan target audience yang merupakan anak remaja.

Melalui pesan yang ditampilkan pada karya audio visual film animasi ini bermaksud ingin memperkenalkan kesenian Indonesia di bidang pewayangan khususnya tokoh Punakawan kepada anak dan remaja untuk memberikan nilai edukasi dengan menggunakan sebuah media yang mudah untuk dipahami dan diterima oleh masyarakat dan menimbulkan dampak positif yang mampu memberikan rasa ingin tahu dan bahkan mampu menggugah perasaan masyarakat mengenai kesenian pewayangan dengan menggunakan mediasi tokoh wayang Punakawan.

\section{METODE PENELITIAN}

Jenis penelitian yang dilakukan dalam penelitian ini adalah jenis kualitatif karena meneliti tentang asal-usul yang membutuhkan banyak referensi dari buku, skripsi, jurnal, observasi dan juga narasumber dari pelaku dan budayawan wayang.

Definisi penelitian deskriptif kualitatif adalah penelitian yang bermaksud untuk memahami fenomena tentang apa yang dialami oleh subjek penelitian, misalnya perilaku, persepsi, motivasi, tindakan, dan lain-lain secara holistik dan dengan cara deskripsi dalam bentuk kata-kata dan bahasa, pada suatu konteks khusus yang alamiah dan dengan memanfaatkan berbagai metode alamiah (Moleong, 2014: 6).

\section{HASIL DAN PEMBAHASAN}

\section{Tokoh Wayang Punakawan}

Menurut Kresna (dalam Prayoga et al., 2015: 1) wayang merupakan salah satu puncak karya seni budaya bangsa Indonesia yang paling menonjol diantara banyak karya seni lainnya. Wayang terus berkembang dari zaman ke zaman, yang juga merupakan salah satu media penerangan, dakwah, pendidikan, hiburan, pemahaman filsafat serta hiburan.

Secara etimologi, Panakawan berasal dari kata pana yang memiliki pengertian cerdik, mengetahui, paham, jelas sekali atau cermat dalam pengamatan. Ensiklopedi Nasional Indonesia (dalam Sunarto, 2012: 242) mengungkapkan bahwa pana berasal dari kata purna yang memiliki arti sempurna atau tuntas, dan menurut Zoetmulder (dalam Sunarto, 2012: 242) kata kawan yang berarti teman. Dengan demikian Panakawan memiliki pengertian sebagai teman atau pamong yang sangat cerdik, dapat dipercaya, mempunyai pandangan yang luas serta pengamatan yang tajam dan cermat. Arti Panakawan menurut Mulyono (dalam Sunarto, 2012: 242) adalah pamong yang tanggaping sasmito lan limpat ing grahito.

Wispra (dalam Sunarto, 2012: 242) mengungkapkan bahwa kelompok wayang ini disebut dengan wayang prepat (parepat), karena tokoh-tokoh dalam kelompok ini berjumlah empat yang senantiasa dijadikan kawan untuk berunding dalam segala masalah sulit dan pelik yang 
dihadapi oleh tokoh satrianya. Di samping itu kelompok wayang ini dinamakan wayang dagelan, karena kelompok wayang ini senantiasa dijadikan alat untuk ndagel atau melawak oleh dhalang.

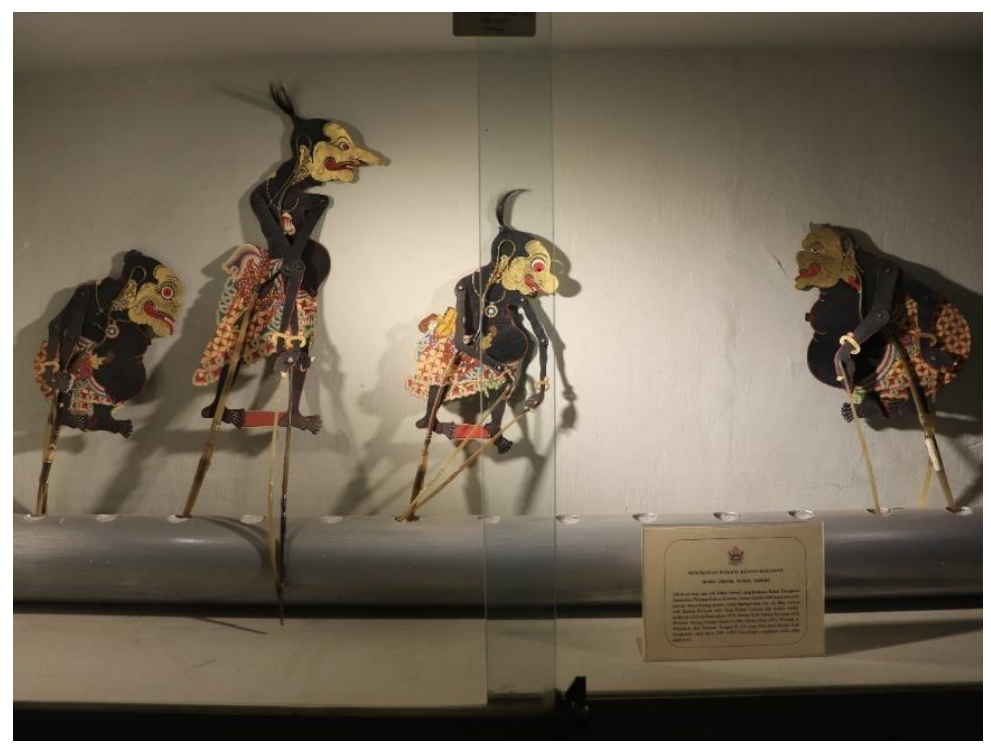

Gambar 1. Tokoh Punakawan

Wayang diungkapkan (Endraswara, 2003:3) merupakan bentuk kesenian Jawa yang masih hidup, masih dihidupi, dan menghidupi. Wayang juga dapat diartikan sebagai salah satu kekayaan budaya yang bernilai seni tinggi. Kehadiran Wayang di tengah-tengah masyarakat sejatinya mampu memberikan peranan penting dan manfaat yang sangat besar bagi kehidupan manusia baik sebagai penyedap pertunjukan maupun sebagai prasarana dalam penyampaian pesan-pesan dan moral-moral. Secara filosofis wayang merupakan bentuk pencerminan karakter manusia, tingkah laku, dan kehidupannya. Salah satu contoh wayang yang sampai saat ini masih hidup dan oleh masyarakat Indonesia dijadikan sebagai suri teladan dan panutan hidup adalah Punakawan. Merupakan dunia wayang asli Indonesia yang terdiri atas Semar, Nala Gareng, Petruk, Bagong, yang dibuat sedemikian rupa mendekati kondisi masyarakat Jawa yang beraneka ragam karakternya yang mengondisikan sumber kebenaran dan kebijakan. Kesenian wayang merupakan tradisi kebudayaan dan sekaligus sebagai hiburan yang digemari masyarakat Indonesia khususnya masyarakat Jawa. Kesenian wayang memiliki kedudukan yang penting dalam masyarakat Jawa dan cerita-cerita dalam wayang itu berisi renungan-renungan tentang ekstensi kehidupan manusia dengan Tuhanya, hubungan antara sesama manusia, hubungan dengan kekuatan alam, dan kekuatan supra alam.

\section{Konsep Perancangan}

Konsep perancangan film animasi asal usul Punakawan dibuat dalam bentuk 2D (dimensi). Film animasi ini dibuat dengan ukuran resolusi 1080 x 720 pxl kualitas hd dalam format mp4. Film animasi Punakawan dirancang untuk memperkenalkan asal usul setiap karakter tokoh dalam Punakawan, yang di dalamnya memiliki pesan moral bagi anak-anak, rencana penempatan media tayang yang digunakan berupa Film Animasi yang sudah dibuat ke dalam bentuk keeping Compact Disk (CD) dan di distribusikan ke beberapa sekolah di wilayah DKI Jakarta dan Depok untuk dijadikan media pembelajaran anak-anak.

\section{Mind Mapping}

Langkah awal dalam penyusunan konsep visual, dilakukan pemetaan pikiran (mind mapping) dari objek penelitian sebagai dasar dalam menemukan kata kunci (keywords) yang dapat digunakan pada hasil karya untuk media utama dan media pendukungnya. Pemetaan pikiran 
(mind mapping) yang dihasilkan berdasarkan data observasi, wawancara dan studi literatur adalah sebagai berikut:

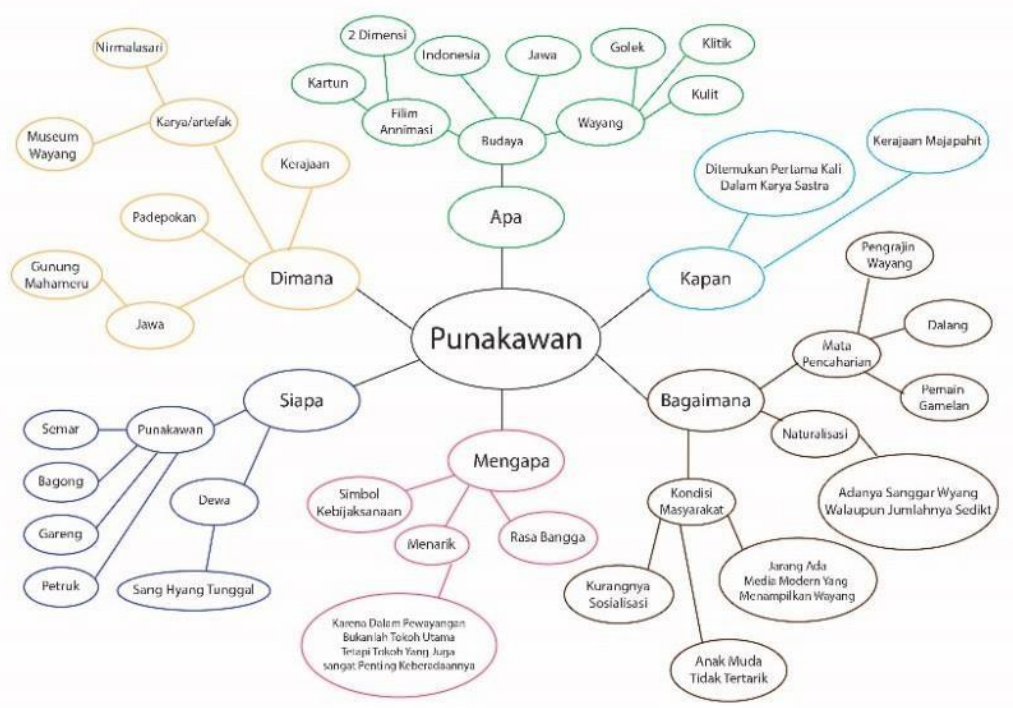

Gambar 2. Mind Mapping

Story Board Asal Usul Punakawan

Tabel 1. Story Board Animasi

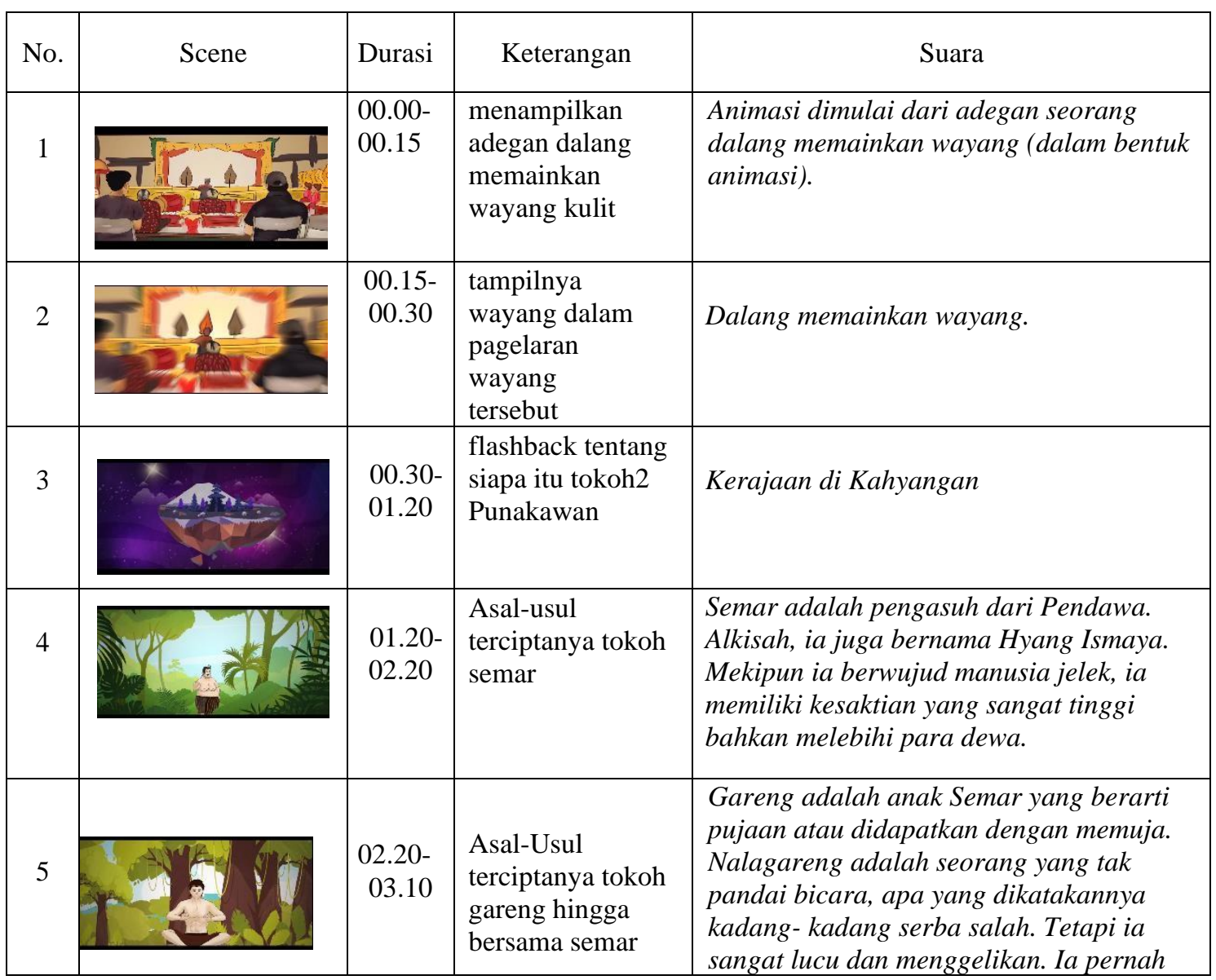




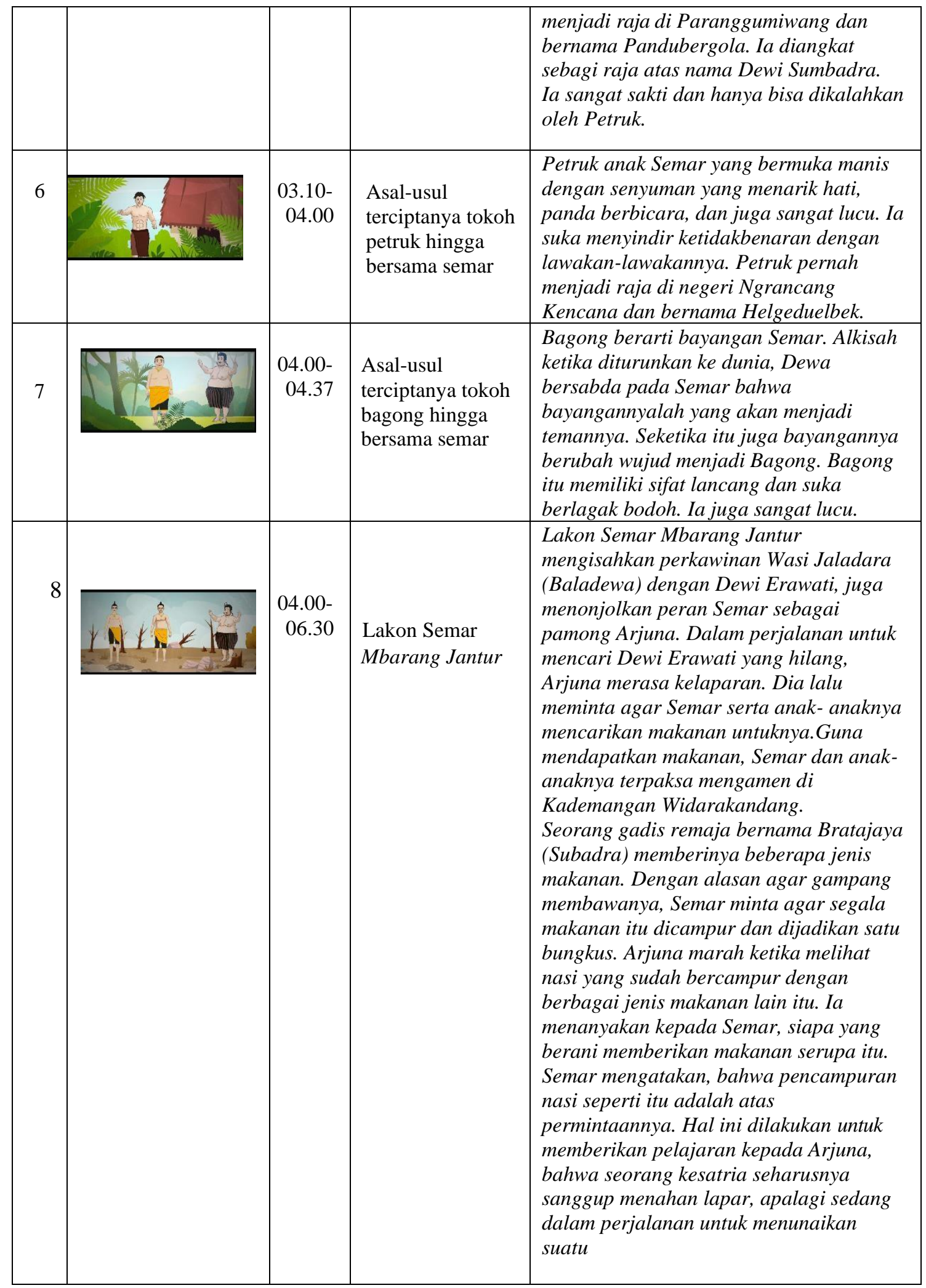

\section{Hasil Perancangan}

Menurut Berikut adalah hasil akhir dari perancangan film animasi Punakawan, beserta dengan penjelasan tentang tampilan visual maupun penggunaanya: 

a. Judul Film Animasi : ASAL-USUL PUNAKAWAN
b. Jenis Film
Animasi 2 Dimensi
c. Format Program : $1280 \times 720$ Pxl
d. Durasi : 5 Menit
e. Software : $\quad 1$. Adobe Illustrator
2. Adobe After Effect
3. Clip Studio Paint
4. GIMP
5. Adobe Premiere Pro
6. Adobe Media Encoder

Teknik perancangan film animasi dimulai dari menentukan pose $3 D$, sketsa, outline, dan pewarnaan menggunakan aplikasi clip studio paint kemudian dimasukkan ke tahap menggerakan animasi, dengan menggunakan metode frame by frame atau menggunakan satu persatu setiap frame dengan menggunakan software clip studio paint dalam tahap ini setiap adegan di gerakan mulai dari tokoh kemudian latar suasana setelah dirender hasil render tersebut diconvert menjadi gif menggunakan aplikasi GIMP. Lalu dilanjutkan dengan software adobe illustrator dan digerakkan tau dibuat motion menggunakan software adobe after effect, setelah scene selesai dibuat dilanjutkan proses render melalui aplikasi adobe media encoder. Setelah semua proses pembuatan scene animasi selesai, lalu mulai tahap pengeditan audio dan urutan scene menggunakan aplikasi adobe premiere pro. Setelah selesai tahap editing, video dirender kembali menggunakan adobe premiere pro.

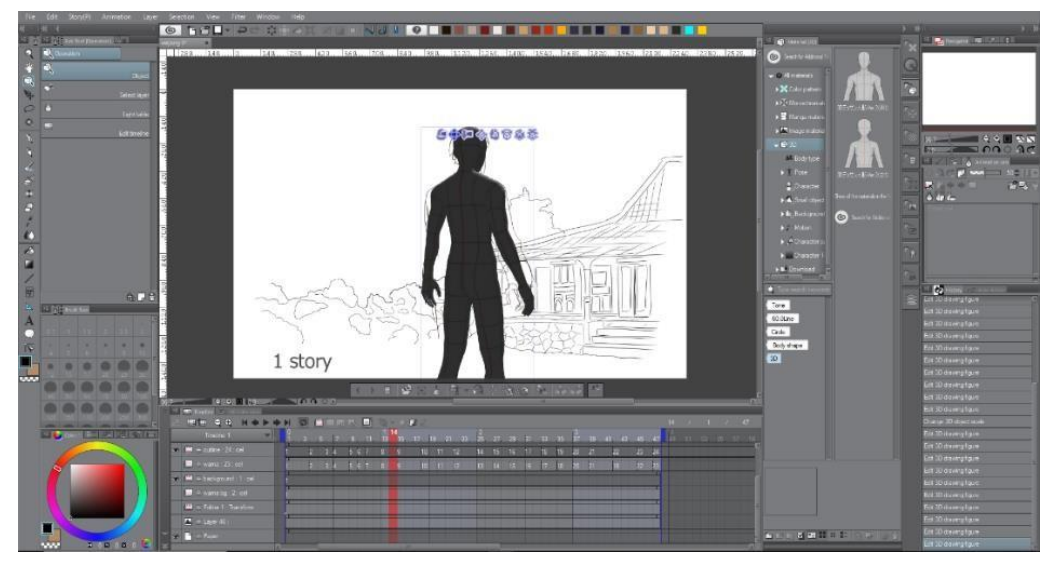

Gambar 3. Proses Sketsa

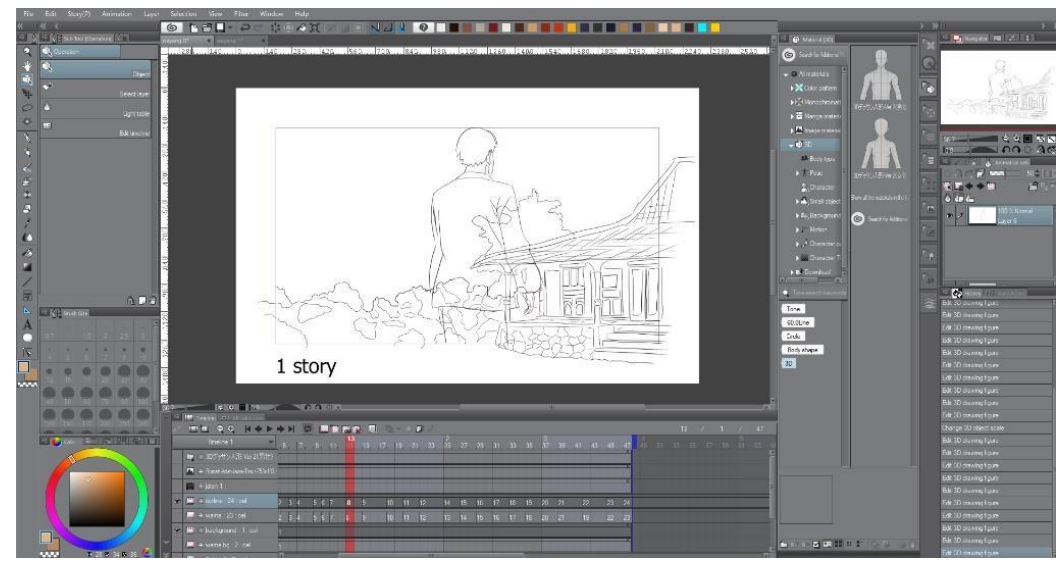

Gambar 4. Proses outline 


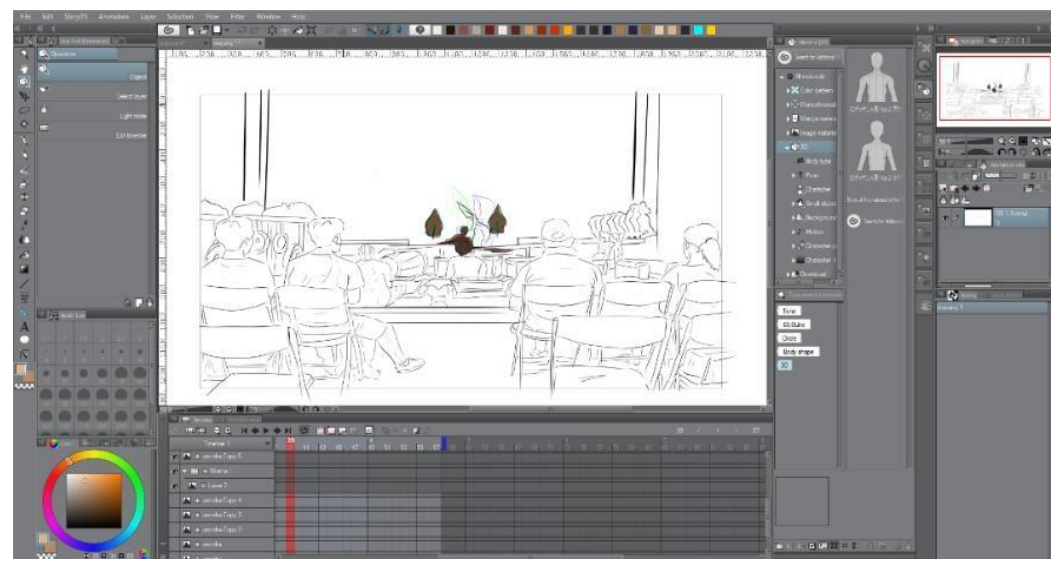

Gambar 5. Proses penggerakan

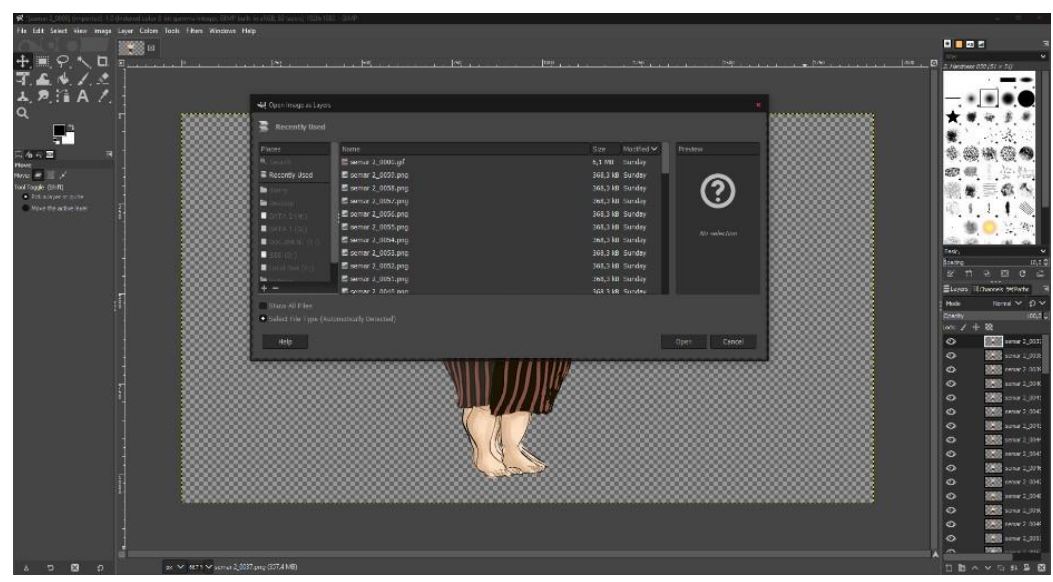

Gambar 6. Proses penggerakan

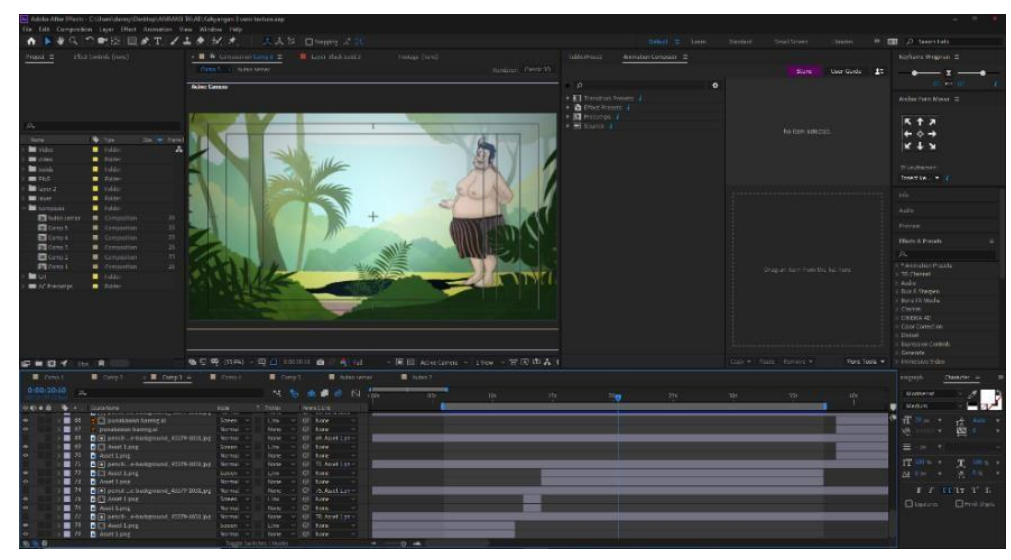

Gambar 7. Proses penggerakan 


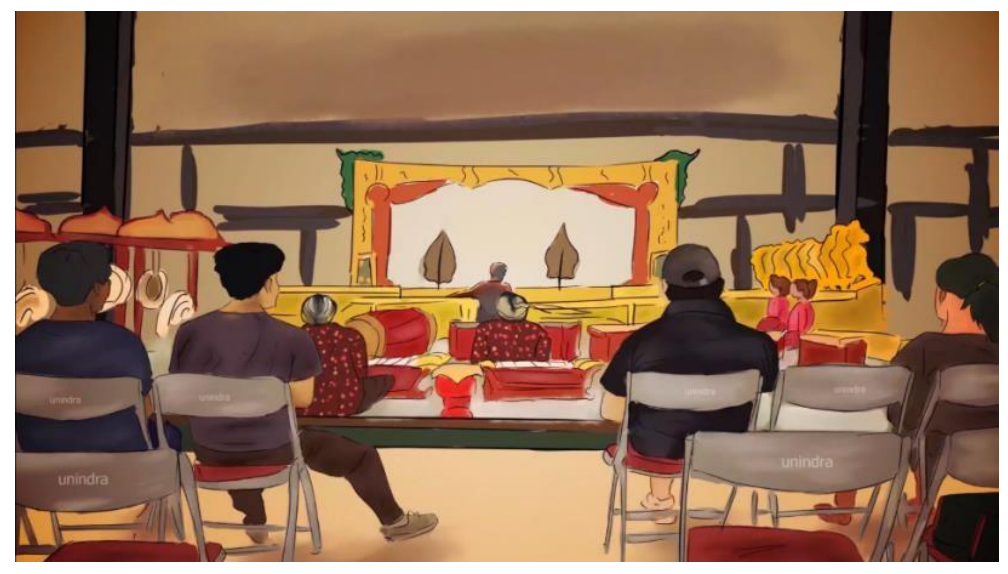

Gambar 8. Printscreen judul

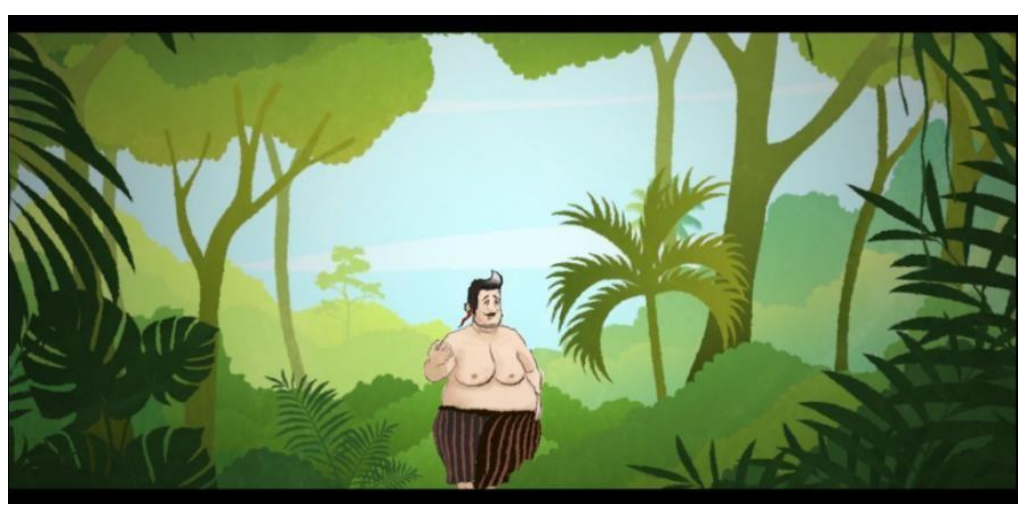

Gambar 9. Printscreen Scene

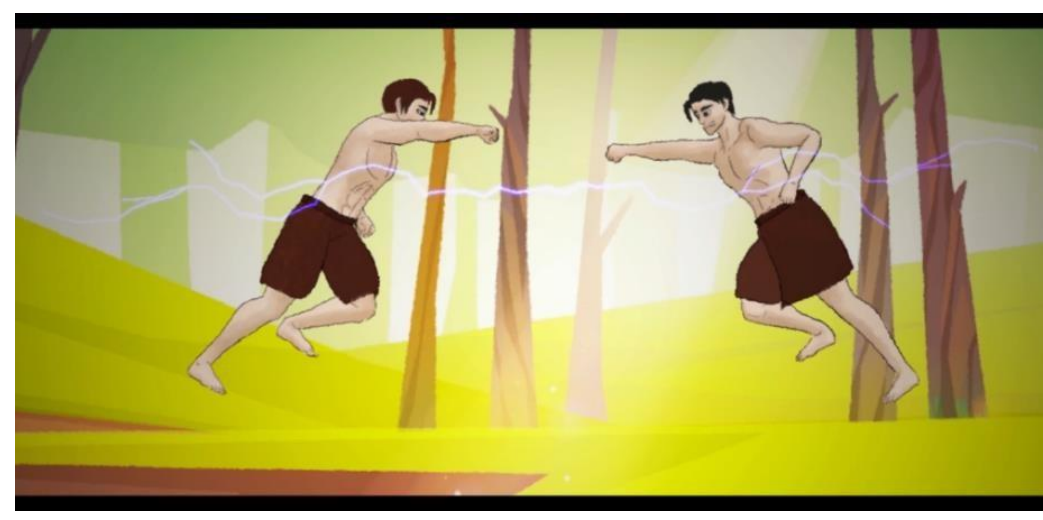

Gambar 10. Printscreen Scene 


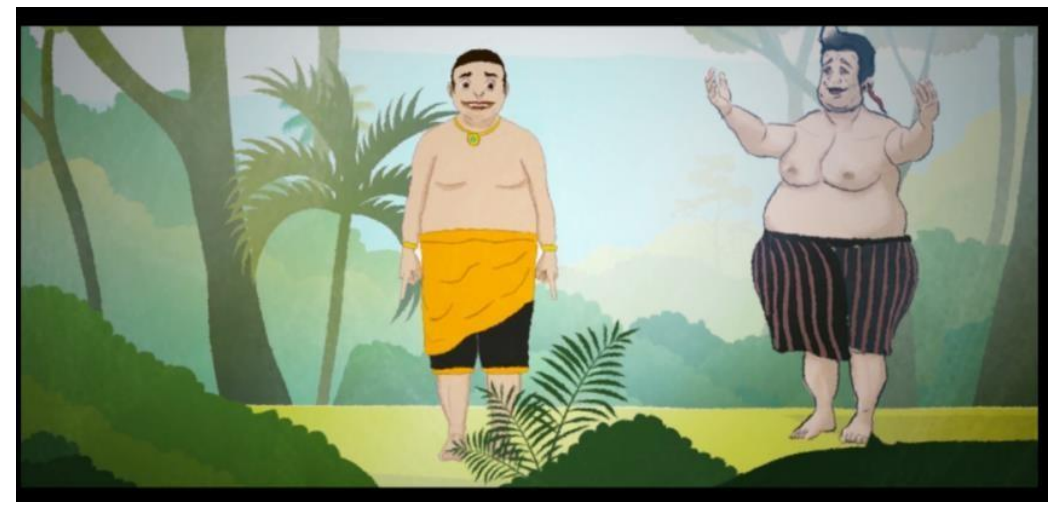

Gambar 11. Printscreen Scene

\section{SIMPULAN}

Berdasarkan penelitian yang dilakukan mengenai perancangan film animasi asal-usul tokoh Punakawan sebagai simbol kebijaksanaan, maka diambil kesimpulan sebagai berikut:

1. Bagi masyarakat, khususnya kepada anak dan remaja untuk menambah wawasan dan ketertarikan mengenai dunia pewayangan yang menjadi adat tradisional Indonesia melalui film animasi, sehingga pelajaran yang didapat dipermudah dengan adanya film animasi.

2. Dengan perancangan media audio visual berupa film animasi yang dibuat dengan kisah dari asal-usul dan cerita hidup tokoh Punakawan mampu memberikan pesan moral serta informasi yang menarik mengenai melestarikan budaya wayang dan mempunyai ketertarikan untuk mempelajari serta melestarikan wayang kepada khalayak luas khususnya kepada anak dan remaja.

3. Karena tujuan yang ingin dicapai adalah menciptakan sebuah media audio visual yang menarik serta efektif sekaligus serta memberikan pengetahuan untuk anak dan remaja. Diharapkan film animasi asal-usul tokoh Punakawan dapat menjawab permasalahan yang ada.

\section{DAFTAR PUSTAKA}

Endraswara, S. (2003). Mistik Kejawen Sinkrestisme Simbolisme dan Sufisme Dalam Budaya Spiritual Jawa. Narasi.

Kresna, A. (2012). Punakawan: Simbol kerendahan hati orang Jawa. Narasi.

Moleong, L. J. (2014). Metodologi Penelitian Kualitatif (Edisi Revi). PT. Remaja Rosdakarya.

Prayoga, D. ., Fianto, A. Y.., \& Hidayat, W. (2015). Penciptaan Buku Novel Graphic Punakawan sebagai Upaya Pengenalan Warisan Budaya kepada Anak-anak. Institut Bisnis dan Informatika STIKOM Surabaya.

Saptodewo, F. (2015). Mempopulerkan Cerita Pewayangan Di Kalangan Generasi Muda Melalui Motion Comic. Desain, Vol 2 No 3, 145-156. https://journal.lppmunindra.ac.id/index.php/Jurnal_Desain/article/view/580/546

Sunarto. (2012). Panakawan Wayang Kulit Purwa: Asal-usul dan Konsep Perwujudannya. Jurnal Seni Dan Budaya Panggung.

Wangi, S. (1999). Ensiklopedi Wayang Indonesia Jilid 5 (T U W Y DAN Lakon). Sekretariat Nasional Pewayangan Indonesia. 